

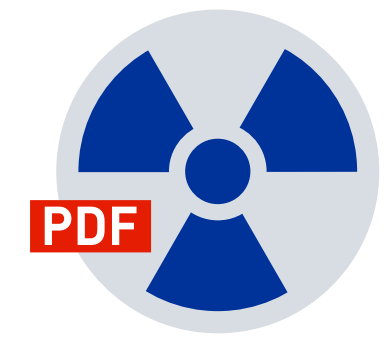

\section{REALOBJECTS PDFreactor $^{\oplus}$}

\section{Evaluation Version}

This PDF document was created by an evaluation version of RealObjects PDFreactor 10.2.10722. The evaluation version is fully functional, but includes this information page. It must not be used for production purposes. The information page and all other evaluation notices must not be removed from the PDF file.

NOTE: Conversions in evaluation mode might be slower and the results might have a larger file size than in production mode.

\section{Buy PDFreactor}

PDFreactor has detected 4 CPU cores, which means you need 1 license pack to use PDFreactor.

To buy a PDFreactor license follow this link:

\section{Buy PDFreactor online}

\section{About PDFreactor}

RealObjects PDFreactor is a powerful formatting processor for converting HTML and XML documents into PDF. It uses Cascading Style Sheets (CSS) to define page layout and styles. The server-side tool enables a great variety of applications in the fields of ERP, eCommerce and Electronic Publishing.

PDFreactor supports HTML5, CSS3 and JavaScript.

It allows you to dynamically generate PDF documents such as invoices, delivery notes and shipping documents on-the-fly. PDFreactor allows you to easily add server-based PDF generation functionality to your application or service. Since PDFreactor runs on a server, the end-user in general does not need any software other than a PDF viewer.

For more information visit www.pdfreactor.com 

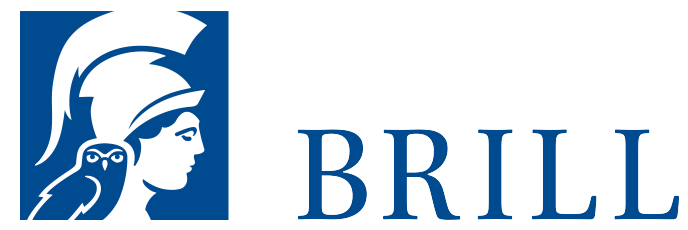

\title{
The Old Japanese Complement System
}

\author{
A Synchronic and Diachronic Study \\ Author: Janick Wrona
}

The present study is the first large-scale investigation of the syntax of Old Japanese (mainly eighth-century Japanese). It gives a detailed account of complement clauses and related constructions in Old Japanese, based on an exhaustive investigation of the extant text corpus. The aim is twofold: first, to give a synchronic description of the types of complementation which are found in this period and of the system they are part of. Second, to address the diachronic issues of the origin of the Old Japanese complement system and more widely the pre-history of complementation in Japanese. Janick Wrona's study will be of interest to historical linguists and Japanologists alike.

\section{Readership}

Professional and scholarly.

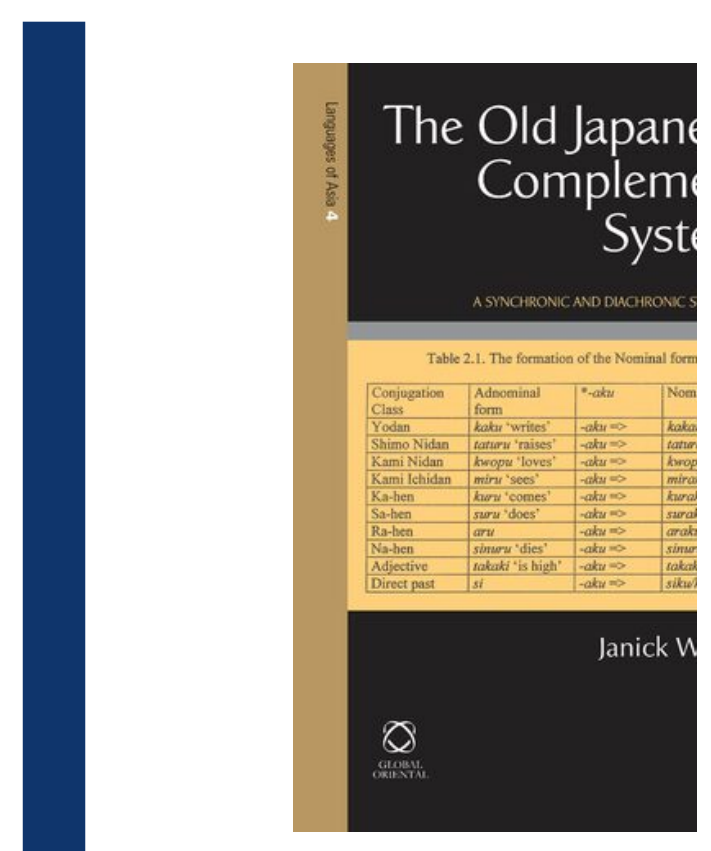

Pages: $524 \mathrm{pp}$.

Language: English

Subjects: Japan, Asian Studi Publisher: Brill

Series: Languages of Asia, $V_{\text {, }}$ E-Book (PDF)

Released online: 15 May 201 ; ISBN: 978-90-04-21318-O

\section{List price}

USD \$202.00

Hardback

Publication date: $03 \mathrm{Jul} 200 \mathrm{~A}$ ISBN: 978-19-01-90319-5

List price

USD \$2O2.00 
Janick Wrona obtained his D.Phil. in Japanese linguistics from the University of Oxford in 2004. He taught Japanese language and linguistics at the University of Copenhagen until taking up the position of postdoctoral fellow at the Department of Linguistics, Kyoto University in 2006.

Alexander Vovin, Professor of East Asian Languages at the University of Hawaii at Manoa, has published extensively on Japanese, Ainu, Korean and Tungusic, as well as other languages of East and Inner Asia. Among his major works are $A$ Reconstruction of Proto-Ainu (Brill, 1993), A Reference Grammar of Classical Japanese Prose (RoutledgeCurzon, 2003) and Nihongo Keitoron no Genzai/Perspectives on the Origins of the Japanese Language (co-edited with Osada Toshiki, the International Center for Japanese Studies, Kyoto, 2003).

For more information see brill.com

Order information: Order online at brill.com +44330 3330049 | customerservices@brill.com Submission information: brill.com/authors

Titles published by Brill | Fink, Brill | mentis or Brill | Schöningh: +49(o)715413279216| brill@brocom.de 